\title{
EHR-related alert fatigue: minimal progress to date, but much more can be done
}

\author{
Thomas H Payne
}

Department of Medicine, UW Medicine Center for Scholarship in Patient Care Quality and Safety, University of Washington, Seattle, Washington, USA

\section{Correspondence to}

Dr Thomas H Payne, UW Medicine Information

Technology Services, Box 359968, 325 Ninth Ave, Seattle, WA 98104-2499, USA; tpayne@u.washington.edu

Received 11 September 2018 Accepted 11 September 2018 Published Online First 8 October 2018

\section{Sinked}

- http://dx.doi.org/10.1136/ bmjqs-2017-007447

\section{Check for updates}

(c) Author(s) (or their employer(s)) 2019. No commercial re-use. See rights and permissions. Published by BMJ.

To cite: Payne TH.

BMJ Qual Saf 2019;28:1-2.
In BMJ Quality \& Safety, Shah et al report their evaluation of the degree to which efforts in the US Veterans Health Administration to reduce electronic health record (EHR)-related information overload have achieved their goal. ${ }^{1}$ Studying the Veterans Health Information System and Technology Architecture (VistA), an internally developed EHR platform used throughout the Department of Veterans Affairs (VA) system, Shah and colleagues report that the median number of mandatory notification types at each VA facility decreased from 15 (IQR 13-19) to 10 (IQR 10-11) preintervention to postintervention, respectively $(\mathrm{p}<0.001)$. And, mean daily notifications per primary care physician decreased significantly from 128 to 116 ( $\mathrm{p}<0.001)$.

I have several reactions to this contribution on EHR-related notifications to clinicians. The first is gratitude for devoting effort towards reducing physician burden and improving safety. A great deal has been written on shortcomings of EHRs and how dissatisfied physicians are with using them. There are fewer carefully designed efforts to address these problems, and we need more of them.

My next thought is that this work, while helpful, was conducted 18 years after use of the VistaA EHR (also known as the Computerised Patient Record System (CPRS)) on which this work was based became widespread within the VA health system, used by many thousands of physicians to care for millions of patients. Moreover, it appears about the time Secretary of Veterans Affairs Robert Wilkie has announced that CPRS is to be replaced with a commercial EHR. ${ }^{2}$ View Alerts have been a fundamental feature of CPRS since it appeared in 1997 with national rollout in 2000. This is in no way a criticism of the authors, but rather of our larger community. Many of us working in healthcare information technology - researchers, users and vendorsshare some responsibility for the pickle in which we find ourselves with the current state of EHRs.

My third reaction is that we have enormous potential for many more substantial improvements in EHRs. In my city of Seattle, just this week, our local paper published an article about a new convenience store opening without human checkout cashiers. How is this done? Using unobtrusive technology within the store and very powerful backend computation. Databases keep track of what purchases each customer has made in the past that help predict what they are likely to purchase today and combined with sensors in the store creates a checkout list automatically. ${ }^{3}$ All of this took a great deal of creativity and a clean-slate approach. Contrast this with the current state most drug decision support in EHRs: we match a newly ordered drug pairwise with drugs on the medication list to determine whether or not to interrupt an ordering physician. The logic rarely includes the age of the patient, comorbidities that might influence risk, the setting in which the new medication will be used (an intubated patient in the intensive care unit or healthy outpatient), and we do not consider whether the same alert has appeared twice in the last hour to the same provider or whether it has been overridden once before or a thousand times. ${ }^{4}$

Improvements reported in the current study leave us better off, but I wonder if physicians will notice. The paper shows a modest improvement in reduction in the number of daily alerts, from 124 per day to 116, which while statistically significant, 
is less than a $10 \%$ reduction. But it is data entry, particularly documentation, that is a major source of physician dissatisfaction with EHRs in a RAND study ${ }^{5}$ and that contributes most to additional time burden of EHRs. ${ }^{6}$ Those documentation tasks remain, mostly involving the persistent use of the keyboard to type notes, even for those for whom typing is not a comfortable means to create notes. Other burdens faced by physicians include the avalanche of notes, lab results, medication and problem lists coming from other sources and requiring attention. This is the down side of interoperability - that we have to reconcile, review and in short, pay much more attention to information which previously was not available to us. Moreover, we have to review this new information using tools and interfaces which are often awkward from a usability perspective. Then we have to enter orders by navigating screens and options which many physicians do not find intuitive. So, a modest reduction in managing alerts may not do as much as we might hope in reducing the burden EHRs place on physicians.

All of this has to do with the quality and safety of care. Overburdened and stressed physicians may burn out or retire early, depleting the number to care for our progressively ageing population. Physicians overwhelmed with data miss important findings that they would otherwise act on. ${ }^{7}$ This is not safe.

We have made such progress in adopting EHRs. In less than a decade we have, as a country, moved from paper to electronic systems joining physicians across the globe, notably the UK, which made this transition in the ambulatory clinics earlier than we did. We did this with a vision that we could leverage technology to improve quality in so many ways. We could improve selection of antibiotics aided by a system that gathers microbiology and laboratory results and local sensitivity results to aid in a complex decision. ${ }^{8}$ We know that carefully crafted alerts can identify hospitalised patients with declining kidney function, and when prompted to alter the medication regimen appropriately, physicians act on this information. ${ }^{9}$ We learnt simple ways to avoid duplicate testing by relying on physician's judgement to define whether or not tests are duplicative. ${ }^{10}$ And we have learnt that diagnostic decision aids can help us, and though we need this more than ever to avoid diagnostic errors, ${ }^{11}$ this fundamental work was conducted over 30 years ago. ${ }^{12}$ The commercial EHRs I use today do not have any of these features, but they could.

And so is the type of improvement documented by Shah and colleagues 'too little too late'? I do not believe it is. It is not enough, but it is certainly not too late. We could still decide that we are going to build on our EHR platforms so that they better realise the potential that led to the widespread decision to adopt EHRs in the first place.

Funding The authors have not declared a specific grant for this research from any funding agency in the public, commercial or not-for-profit sectors.

Competing interests None declared.

Patient consent Not required.

Provenance and peer review Commissioned; internally peer reviewed.

\section{REFERENCES}

1 Shah T, Patel-Teague S, Kroupa L. Impact of a national QI programme on reducing electronic health record notifications to clinicians. BMJ Qual Saf 2019;28:10-4.

2 Healthcare IT News, 2018. VA officially signs with Cerner on EHR modernization project. Available from: https://www. healthcareitnews.com/news/va-officially-signs-cerner-ehrmodernization-project (accessed 31 Aug 2018).

3 Bishop T, 2016. How 'Amazon Go' works: the technology behind the online retailer's groundbreaking new grocery store. Available from: https:/www.geekwire.com/2016/amazon-goworks-technology-behind-online-retailers-groundbreakingnew-grocery-store/ (accessed 31 Aug 2018).

4 Payne TH, Desai BR. Examination of medication clinical decision support using Bayes' theorem. Am J Health Syst Pharm 2016;73:1876-8.

5 Friedberg MW, Chen PG, Van Busum KR, et al, 2013. RAND RESEARCH REPORT: Factors affecting physician professional satisfaction and their implications for patient care, health systems,and health policy. Available from: https://www.rand. org/pubs/research_reports/RR439.html (Accessed 28 Sep 2018).

6 Sinsky C, Colligan L, Li L, et al. Allocation of physician time in ambulatory practice: a time and motion study in 4 specialties. Ann Intern Med 2016;165:753-60.

7 Singh H, Spitzmueller C, Petersen NJ, et al. Information overload and missed test results in electronic health recordbased settings. JAMA Intern Med 2013;173:702-4.

8 Evans RS, Pestotnik SL, Classen DC, et al. A computer-assisted management program for antibiotics and other antiinfective agents. N Engl J Med 1998;338:232-8.

9 Rind DM, Safran C, Phillips RS, et al. Effect of computerbased alerts on the treatment and outcomes of hospitalized patients. Arch Intern Med 1994;154:1511-7.

10 Tierney WM, McDonald CJ, Martin DK, et al. Computerized display of past test results. Effect on outpatient testing. Ann Intern Med 1987;107:569-74.

11 Schiff GD, Bates DW. Can electronic clinical documentation help prevent diagnostic errors? N Engl J Med 2010;362:1066-9.

12 Miller RA, Pople HE, Myers JD. Internist-1, an experimental computer-based diagnostic consultant for general internal medicine. N Engl J Med 1982;307:468-76. 